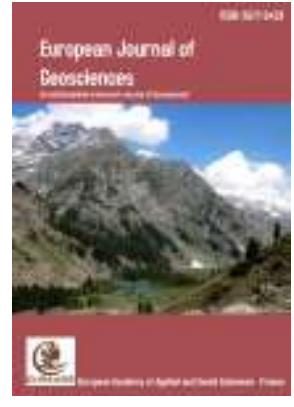

Research Article

\title{
Analysis of drought and wet season in Guilan province using SPI relationship and Markov chain model
}

\section{Abbas Kashani*, Zahra Arabi ${ }^{\mathrm{b}}$, Gholam Abbas Fallah Ghallharic, Bromand Salahi $^{\mathrm{d}}$}

\author{
${ }^{a}$ Department of Climatology, Faculty of Natural Geography, Mohaghegh University Ardabili, Ardebil - Iran. \\ ${ }^{b}$ Associate Professor at Payame Noor University, Tehran - Iran. Email: arabiza1394@gmail.com \\ ${ }^{c}$ Hakim Sabzevari and Shiraz University, Shiraz - Iran. Email: ab_fa789@yahoo.com \\ ${ }^{d}$ University of Mohaghegh Ardabili, Ardabil - Iran. Email: bromand416@yahoo.com
}

Received: 10 December 2020 / Revised: 11 January 2021 / Accepted: 21 January 2021

\begin{abstract}
Drought is an urgent environmental issue. Therefore, recognizing its characteristics is of great importance. The most common drought monitoring tool is the Drought Index. The SPI index is a well-known indicator of drought monitoring because of its simplicity, versatility and applicability in any type of climate. In order to investigate the dry matter and estimate its occurrence probability in Rasht city, which is located in the most rainy part of Iran, the time series of SPI were used in combination with Markov chain and the continuity, severity and frequency of dry and wet periods for the period 12.6 .3 and 24 months old. The probability of equilibrium in each of the dry and wet conditions and the normal and the expected average expected drought and mildew were predicted, together with the average duration of its duration for different periods. The results showed that the drought share of mild droughts in all periods and droughts Severe is more than 6 months longer. Drought is the highest in the 3rd and 6th month period and is the lowest in the 24-month period. The continuation of drought is greater in the 12 and 24-month intervals, and the probability of transition from one state to another is increased in a longer time series. The probability of equilibrium is more than drought. The SPI profile matches the results of the Markov chain, so combining these two, while improving our ability to evaluate drought monitoring, increases the efficiency of the management system and resource planning.
\end{abstract}

Keywords: Drought and Tolerance, SPI Index, Markov Chain, Guilan Province.

(c) Euraass 2021. All rights reserved.

\section{Introduction}

Drought is a natural part of the climate, although it may be considered a rare and accidental mistake that has a significant impact on the environment and society. Because the period of dryness and low rainfall will be temporary, this climatic period is a natural climatic period. And in these climatic conditions, so it can occur in any climatic zone (Nielsen, 2007). Drought is a multifaceted phenomenon that has become an important environmental issue (Folger, 2013).

* Corresponding author: Email: abasskashani122@uma.ac.ir (A.Kashani).

Available online: 25 January 2021

DOI: https://doi.org/10.34154/2021-EJGS-0014/euraass

Journal reference: Eur. J. Geosc. 2021, 03(01), 19 - 30.

ISSN-E: 2677-643X.

(c) European Academy of Applied and Social Sciences. Euraass - 2020. All rights reserved.

Cite as: Kashani, A., Arabi, Z., Ghallhari, G. A. F., Salahi, B. (2021). Analysis of Drought and Wetland Study in Gilan Province Using Markov Chain Model, SPI. Eur. J. Geosc. 03(01), 19-30. 
One of the concerns raised in recent years around the world is that droughts are on the rise as a result of climate change, and that their number, sustainability, and severity depend on long-term climate change in recent historical periods. , And thus, the social vulnerabilities caused by these changes in increasing climate and drought (WMO-GWP) need to be Climate indicators such as: degree, severity, duration, occurrence and end of drought, and their time distribution and place, led the researchers to identify indicators. Therefore, the identification of drought indicators is the first step in monitoring drought conditions. They help us identify and determine the types of droughts (Nielsen, 2007). Using drought indices for each drought, time, intensity and spatial extent can be defined. They can be used to describe all types of drought (Tsakiris et al., 2012).

Determining dry or wetland characteristics in a region is one of the basic requirements of environmental and economic planning, especially planning for water resources management? In many planning, it is necessary to look at the future state of rainfall and dry periods. More for the area Draw up For this reason, the subject of drought forecasting and its characteristics is of great importance in water resource management Mckee, et al. (1993). Have standardized precipitation index (SPI) for the definition and monitoring of drought and the determination of rainfall shortage for the time periods of $(3,6,12,24,48)$ months has expanded (Mckee et al., 1993).

Combining the analysis of time series with standardized rainfall index increases its ability to detect and justify drought characteristics in each location. Because this method It needs a few variables to calculate and have the ability to monitor close to real time (monthly), this SPI index is in a very good position compared to other indicators. In addition, the index is standardized dynamic dynamics and can be calculated in different time intervals (Fattahi and Honesty, 2007). Heidari and Yazdani (2001) researches in Iran show that seasonally adjusted precipitation index (SPI) has better performance than other indicators..

One of the most important things to consider when considering a drought is the likelihood of it occurring. Therefore, the use of time series models, such as the Markov chain model, can be useful in achieving the researcher's goal. The simple Markov chain facilitates mathematical methods for solving probabilities related to dependent processes and is used in various sciences. Using the Markov chain model in the Palmer time series in the United States, Thompson (1990) showed that this model can be used to predict dry and wet periods. The trend of changes in drought severity in southern Portugal was studied using the SPI time series and the Markov chain, by Paulo et al. (2003-2005). Gabriel and Newman used the first-order Markov chain model to determine dry days, and in Occupied Palestine, Yousefi and Irannejad (2007) used the first-order Markov chain model and normal distribution to estimate the probability of drought in Qazvin. The results of using the Markov chain model were superior to the probabilities derived from using the normal distribution. Rezaei et al. (2007) using Spi profile and Markov chain probability of drought and its spread in Sistan and Baluchestan and concluded that on a six-month scale, the risk of drought in the central region of Sistan and Baluchestan is higher. Sadeghi et al. (2011), in comparison with its eastern regions, by combining the Spi index with the Markov chain, estimated the probability of drought in Tehran and concluded that the probability of drought occurring after each dry period is more than the probability of occurrence one year after Each wet period, on the other hand, because the causes and consequences of regional droughts are different, it is necessary to customize drought information in terms of regions. In the present study, we use the first-order Markov chain model to identify dry and wet periods of SPI and to predict the series of rotation times. The spi calculation method and the Markov chain model are introduced.

This research is related to the city of Rasht as the center of Guilan province, which is known for its cloudy sky and its rainy days. Because it is hard to imagine that in this area there is a dilemma in the area of general education and even those who are in the field of college education, this study attempted to find out from the angles of this creepy and mysterious phenomenon In the region, it will open up a special attention of officials to manage its effects in the area.

\section{Research method}

Initially, the data of Guilan Meteorological Department on a monthly scale during the statistical period (1956-2005) were analyzed homogeneously and randomly in Excel and SPSS environments. The results of the hip test confirmed the homogeneity of the data, based on which the randomness of the data was accepted at $95 \%$ confidence level and $\alpha=5 \%$. The statistical deficiencies of the station were corrected using the normal ratio method based on the data of Anzali base station. Due to the slope of the data, to normalize the data and calculate the spi, they were entered into the spi-sl- 6 software environment and the desired time series of 3, 6,12 and 24 months were selected. This software has performed all the necessary computational steps to convert precipitation data to Z score, SPI. Figure 1 shows that the data are normal and statistically the best fit. 


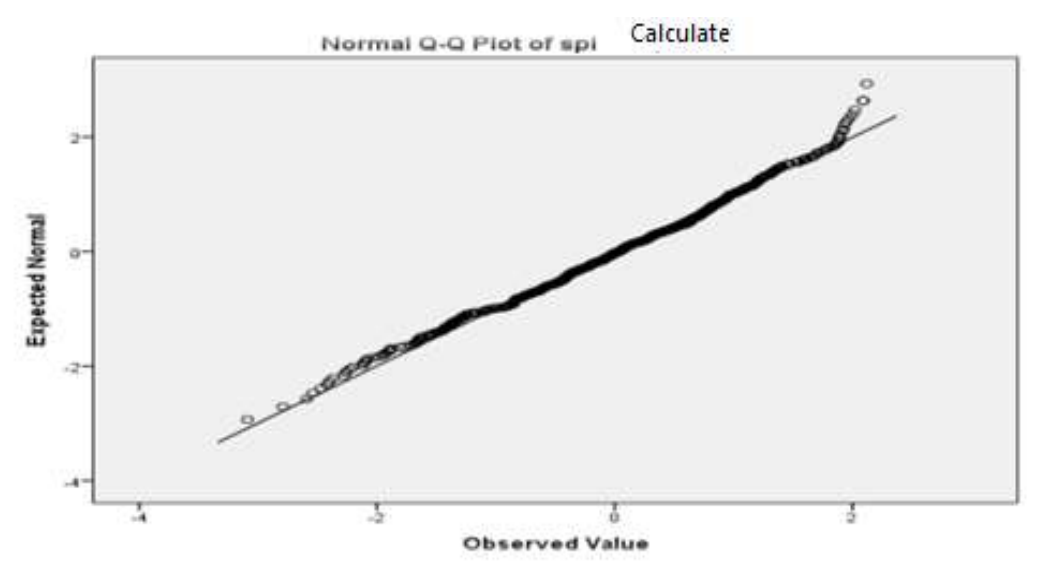

Figure 1: The fitting of rainfall data for Rasht station after converting it to $z$ or SPI.

\subsection{Standardized precipitation index (Spi)}

The index was introduced by McKay and his colleagues in 1993 and used in Colorado in 1997. In fact, this index is designed to determine the numerical value of the rainfall deficit for different time periods, and the time scale indicates the effect of drought on water resources (Monacelli, 2012). The spi index significantly facilitates monitoring and analysis of humidity and rainfall conditions, and provides numerical data on different precipitation rates, allowing for comparison of climatic zones (Hong et al., 2001). In the spi index, the time intervals of 1-3-6-9-12-24-48 are used. The above is to monitor the types of droughts and the effects of each of them. The high sensitivity of spi to the two heterogeneous spatial parameters and the amount of precipitation can make it difficult to use the statistical data of dispersed stations (Nielsen, 2007). The point to be taken into consideration is that it is unreliable if spi intervals are taken over 24 months (Svoboda, 2009). The calculated values of the standardized numbers (z score) are higher and lower than the normal conditions. Due to the lack of a time-based and location-based constraint, the SPI index can estimate the cumulative probability for the base period for which the distribution parameters are estimated (Hejazizadeh and Joyazade, 2010).

\subsubsection{SPI Index Estimation}

Relationship (1) $\quad$ spi $=\frac{\mathrm{p}_{\mathrm{i}}-\overline{\mathrm{p}}}{\mathrm{s}}$

$=$ Amount of precipitation in the desired period

= (-@ P) Average long term precipitation for the period under review s Standard deviation of precipitation

The table below shows the intensity of drought based on the calculated spi values.

Due to the fact that SPI values are not considered at 0 to 0.99 at the onset of drought, this is probably due to the moisture content of the past tense period, but at the end of a drought period it can be a mild drought indicator.

Table 1: Classification of SPI values

\begin{tabular}{cccccccc}
\hline Condition & $\begin{array}{c}\text { Very intense } \\
\text { wet }\end{array}$ & $\begin{array}{c}\text { Intense } \\
\text { wetness }\end{array}$ & $\begin{array}{c}\text { Gentle } \\
\text { wetness }\end{array}$ & Normal & Mild drought & $\begin{array}{c}\text { Mild drought } \\
\text { Very severe } \\
\text { drought }\end{array}$ \\
\hline SPI values & 2 and above & 1.99 to 1.5 & 1.49 to 1 & 0.99 to -0.99 & 1 - to- 1.49 & 1.5 to- 1.99 & $2-$ and less \\
\hline
\end{tabular}

\subsubsection{Markov chain model}

One of the important issues to be considered in drought monitoring is droughts. The Markov chain facilitates related processes with simple mathematical methods for solving probabilities and is used in various sciences, especially meteorology and hydrology (Thompson, 1990). The concept of the Markov chain is that a chain with a series of observations is examined, and the probability that each of them changes from one state to another is determined. The basis of this model is based on the principle that the probability of 
an occurrence of a climatic state at time $t$ depends on its condition at the previous time (t-1). The model is based on the number of modes and transfer probabilities from $\mathrm{i}$ to $\mathrm{j}(\mathrm{Pij})$. Transmission probability indicates the probability that the system will be located in one of the possible ways in the next step. The first-order Markov chain model is the most important form of the model, which is a discrete time series, in which the behavior of the series depends only on the past, and is expressed in the following way.

Relation (2) $\quad \operatorname{Pr}\left[\mathrm{x}_{\mathrm{t}+1} \mid \mathrm{x}_{\mathrm{t}}, \mathrm{x}_{\mathrm{t}-1}, \mathrm{x}_{\mathrm{t}-2}, \ldots, \mathrm{xI}\right]=\operatorname{Pr}\left\{\mathrm{x}_{\mathrm{t}}+1 \mid \mathrm{x}_{\mathrm{t}}\right\}$

where in $p r$ is the probability of a state occurring conditionally. The state variable $t$ is the time step (wilks, 1995). The number of modes in the Markov chain can be changed from two to $\mathrm{N}$ modes. If the possible modes for the SPI time series in this study are three dry (D), normal $(n)$ and wet $(W)$, the system state in the next step can be with the percentage of probability, each of the modes $D, n$, and $W$, which, according to the present situation, is calculated as a conditional probability. Therefore, the first step is to determine the number of dry, normal, and normal periods in the study series. Preparing the transition probability matrix intersections in the second stage (Table 2).

Table 2: Initial matrix of conditional transfers.

\begin{tabular}{cccc}
\hline W & $\mathbf{n}$ & $\mathbf{D}$ & \\
\hline NDW & NDn & NDD & D \\
NnW & Nnn & NnD & $n$ \\
NWW & NWn & NWD & W \\
\hline
\end{tabular}

In this matrix, D is a drought symptom and an SPI value of less than $0.99 . \mathrm{W}$ is the value of the year and the SPI value is greater than 0.99 , and $n$ represents the normal state, with spi in this state between 0.99 and 0.99 . Each of the matrix cells shows a transition state. After counting the number of conditional transfer modes, the matrix of the probability of transferring the desired time series is calculated according to Table 3.

Table 3: Probability matrix for 9 transition modes.

\begin{tabular}{cccc}
\hline $\mathbf{W}$ & $\hat{n}$ & & \\
\hline$p_{\wedge}(\mathrm{DW})$ & $p_{\wedge}(\mathrm{Dn})$ & $\mathbf{D}$ & $\mathrm{D}$ \\
$p_{(\mathrm{nW})}$ & $p_{(\mathrm{nn})}$ & $p_{(\mathrm{nD})}$ & $\mathrm{n}$ \\
$p_{(\mathrm{WW})}$ & $p_{(\mathrm{wn})}$ & $p_{(\mathrm{WD})}$ & $\mathrm{W}$ \\
\hline
\end{tabular}

By substituting the transmission probability values in the following relationships, the probability of equilibrium is calculated for each of the drought (D), wetting (W) and normal (n) states.

Relation (3)

$$
\hat{p} * D=\frac{[\mathrm{P}(D D)+P(W D)+P(n D)]}{\hat{P}(D D)+\hat{P}(D n)+\hat{P}(D w)+\hat{P}(n n)+\hat{P}(n D)+\hat{P}(n w)+\hat{P}(w w)+\hat{P}(w n)+\hat{P}(w D)}
$$

The probability of a dry period's equilibrium, the probability of a transition from a dry period to another dry period, the probability of a transition from a period to a dry period, the probability of passing from a normal period to a dry one.

Relation (4)

$\hat{p}{ }^{*} \mathrm{~W}=\frac{[\mathrm{P}(W W)+P(D W)+P(n W)]}{\hat{P}(D D)+\hat{P}(D n)+\hat{P}(D w)+\hat{P}(n n)+\hat{P}(n D)+\hat{P}(n w)+\hat{P}(w w)+\hat{P}(w n)+\hat{P}(w D)}$

$p^{*} \mathrm{~W}$ The probability of a wet period balance.

Relation (5)

$$
\begin{aligned}
& \hat{p} * \mathrm{n}=\frac{[\mathrm{P}(n n)+P(D n)+P(W n)]}{\hat{P}(D D)+\hat{P}(D n)+\hat{P}(D w)+\hat{P}(n n)+\hat{P}(n D)+\hat{P}(n w)+\hat{P}(w w)+\hat{P}(w n)+\hat{P}(w D)} \\
& \hat{p} * \mathrm{n} \text { The probability of normal period equilibrium. }
\end{aligned}
$$


The next step is to calculate the probability of occurrence of dry, wet and normal periods in the study series in order to determine the corresponding courses in the future. For this purpose, the following relationships can be used to estimate the probability of the event of each drought, mild and normal conditions.

$$
\begin{gathered}
P(D)=\left[P^{*} N \times P(n D)+P^{*} W \times P(W D)\right] \\
P(W)=\left[P^{*}(n) \times P(n W)+P^{*} D \times P(D W V)\right] \\
P(N)=\left[P^{*}(D) \times P(D n)+P^{*} W \times P(W V n)\right]
\end{gathered}
$$

Estimates of the number of dry, normal, and expected periods in the next periods are calculated according to the following relationships:

$$
\text { Relation (6) }
$$

$$
E(D)=P(D) \times t \quad E(n)=P(n) \times t \quad E(W)=P(W) \times t
$$

In the high $E(D)$ relationship, the expectation of math is drought or the average number of expected droughts in the studied period, and so $E(W)$ is the expected math expectation and $E(n)$ is the expected mathematical expectation of the expected normal period in the study period..$t$ is the sample value for each time series. The last step in the Markov chain model is to predict the average drought persistence and the future for the future.

\section{Research Findings}

Dry, normal and normal periods were determined for each time interval and their probability was estimated at the time intervals. The results were presented in Table 4 in percent. In the next step, according to tables 2 and 3 , the matrices of the initial conditional transfer were prepared, and then the probability matrix for each mode was estimated, and the results were presented in the form of tables 5 and 6.

\begin{tabular}{ccccc}
\multicolumn{5}{l}{ Table 4: Estimates of the probability of occurrence of drought, mild and normal conditions to percent } \\
\hline Chance has come (\%) & SPI 3 month & SPI $\mathbf{6}$ month & SPI12 month & SPI24 month \\
\hline P(D) & 15.75 & 15.2 & 15.82 & 16.31 \\
P(n) & 68 & 68.2 & 69.56 & 66.49 \\
P(w) & 16.25 & 16.6 & 14.62 & 17.2 \\
\hline
\end{tabular}

Table 5: Estimates of the probability of occurrence of drought, mild and normal conditions to percent.

\begin{tabular}{cccccccccc}
\hline Conditional Transfer Mode/Period & $\mathbf{P}(\mathbf{D D})$ & $\mathbf{P}(\mathbf{D n})$ & $\mathbf{P}(\mathbf{D W})$ & $\mathbf{P}(\mathbf{n n})$ & $\mathbf{P}(\mathbf{N d})$ & $\mathbf{P}(\mathbf{N W})$ & $\mathbf{P}(\mathbf{W W})$ & $\mathbf{P}(\mathbf{W N})$ & $\mathbf{P}(\mathbf{V D})$ \\
\hline SP1 3 & 0.5 & 0.468 & 0.03 & 0.781 & 0.011 & 0.105 & 0.527 & 0.452 & 0.022 \\
SPI 6 & 0.611 & 0378 & 0.011 & 0.751 & 0.081 & 0.099 & 0.586 & 0.404 & 0.01 \\
SPI 12 & 0.72 & 0.279 & 0 & 0.887 & 0.066 & 0.049 & 0.767 & 0.233 & 0 \\
SPI 24 & 0.838 & 0.162 & 0 & 0.922 & 0.042 & 0.037 & 0.037 & 0.149 & 0 \\
\hline
\end{tabular}

Table 6: Matrix of probability of conditional transfer to another state at different time intervals.

\begin{tabular}{cccccccccc}
\hline Conditional transfer modes/period & $\mathbf{P}(\mathbf{W D})$ & $\mathbf{P}(\mathbf{W n})$ & $\mathbf{P}(\mathbf{W W})$ & $\mathbf{P}(\mathbf{N W})$ & $\mathbf{P}(\mathbf{N d})$ & $\mathbf{P}(\mathbf{n n})$ & $\mathbf{P}(\mathbf{D W})$ & $\mathbf{P ( D n )}$ & $\mathbf{P ( D D )}$ \\
\hline SPI 3 & 0.022 & 0.452 & 0.527 & 0.105 & 0.11 & 0.781 & 0.03 & 0.468 & 0.5 \\
SPI 6 & 0.01 & 0.404 & 0.586 & 0.099 & 0.081 & 0.751 & 0.011 & 0.378 & 0.611 \\
SPI 12 & 0 & 0.233 & 0.767 & 0.049 & 0.064 & 0.887 & 0 & 0.279 & 0.72 \\
SPI 24 & 0 & 0.149 & 0.851 & 0.037 & 0.042 & 0.922 & 0 & 0.162 & 0.838 \\
\hline
\end{tabular}

In order to calculate the equilibrium probability of each of the states $\mathrm{D}, \mathrm{n}, \mathrm{W}$, the obtained conditional transfer probability values were used and the results are presented in Table 7 . In order to calculate the probability of the equilibrium of each of the modes $D$, $n$, W, the conditional transfer probability values were used and the results were presented in Table 8. 
Table 7: Estimated values of equilibrium probability of dry, wet and normal periods in the desired time intervals by Markov chain method - Rasht station.

\begin{tabular}{cccccccccc}
\hline Conditional transfer modes/period & $\mathbf{P}(\mathbf{W D})$ & $\mathbf{P}(\mathbf{W n})$ & $\mathbf{P}(\mathbf{W W})$ & $\mathbf{P}(\mathbf{N W})$ & $\mathbf{P}(\mathbf{N d})$ & $\mathbf{P}(\mathbf{n n})$ & $\mathbf{P}(\mathbf{D W})$ & $\mathbf{P}(\mathbf{D n})$ & $\mathbf{P}(\mathbf{D D})$ \\
\hline SPI 3 & 0.022 & 0.452 & 0.527 & 0.105 & 0.11 & 0.781 & 0.03 & 0.468 & 0.5 \\
SPI 6 & 0.01 & 0.404 & 0.586 & 0.099 & 0.081 & 0.751 & 0.011 & 0.378 & 0.611 \\
SPI 12 & 0 & 0.233 & 0.767 & 0.049 & 0.064 & 0.887 & 0 & 0.279 & 0.72 \\
SPI 24 & 0 & 0.149 & 0.851 & 0.037 & 0.042 & 0.922 & 0 & 0.162 & 0.838 \\
\hline
\end{tabular}

Table 8: Estimated values of dry, wet and normal period balance probabilities over time intervals by Markov chain - Rasht station.

\begin{tabular}{ccccc}
\hline Chance balance/period & $\mathbf{P}^{*} \mathbf{N}$ & $\mathbf{P}^{*} \mathbf{W}$ & $\mathbf{P}^{*} \mathbf{D}$ \\
\hline SPI & 0.565 & $0 . .224$ & 0.211 \\
SPI & 6 & 0.513 & 0.36 & 0.23 \\
SPI 12 & 0.466 & 0.272 & 0.261 \\
SPI 24 & 0.411 & 0.296 & 0.293 \\
\hline
\end{tabular}

In order to determine the number of dry, normal, and expected periods in the future, the probability of occurrence of dry, normal and normal periods in the study series should first be determined. If the environment passes from the state of the normal or to the dry state, in this case Drought occurs, and when the environment goes from dry to normal to wet conditions, it is estimated that the drought, mild and normal drought, has been estimated (Table 9). Then, according to the size of the samples (t), their number in each spi time series on the scale of $3,6,12$ and 24 months is $597,594,588$ and 576 , respectively, the number of dry periods $E(D)$, more $E(W)$ and normal $E(n)$ were expected.

Table 9: Estimated values for the probability of occurrence of dry, wet and normal periods (Time intervals using the Markov chain-Rasht station).

\begin{tabular}{cccc}
\hline $\mathbf{P}(\mathbf{D})$ & $\mathbf{P}(\mathbf{N})$ & $\mathbf{P}(\mathbf{W})$ & \multicolumn{2}{c}{ Possibility / time series } \\
\hline 0.064 & 0.199 & 0.071 & $\mathrm{SPI}$ \\
0.046 & 0.145 & 0.054 & $\mathrm{SPI}$ \\
0.122 & 0.092 & 0.023 & $\mathrm{SPI}$ \\
0.067 & 0.092 & 0.015 & $\mathrm{SPI} 24$ \\
\hline
\end{tabular}

Table 10: Estimation of Average Dry, Wet and Normal Expected Periods for Rasht Station in Each Markov Chain Series.

\begin{tabular}{cccc}
\hline $\mathbf{E}(\mathbf{D})$ & $\mathbf{E}(\mathbf{n})$ & $\mathbf{E}(\mathbf{W})$ & Expectation / Periods of time \\
\hline 38.2 & 11.88 & 42.4 & $\mathrm{SPI}$ \\
27.3 & 86.1 & 32.1 & $\mathrm{SPI} 6$ \\
176.4 & 71.7 & 13.52 & $\mathrm{SPI} 12$ \\
38.6 & 38.6 & 8.64 & $\mathrm{SPI} 24$ \\
\hline
\end{tabular}

In the last stage, the average period of drought persistence and wet period was estimated in each time series, the result was presented in Table 11.

Table 11: Estimation of the average period of drought persistence and wet period for Rasht station Time series by Markov chain method.

\begin{tabular}{cccc}
\hline SPI 3 & SPI 6 & SPI 12 & SPI 24 \\
\hline 2.1 & 2.4 & 4.3 & 6.2 \\
2.1 & 2.6 & 3.6 & 6.7 \\
SPI 3 & SPI 6 & SPI 12 & SPI 24 \\
2.1 & 2.4 & 4.3 & 6.2 \\
\hline
\end{tabular}

Figure 2 shows the contribution of each of the droughts in different time series at Rasht station. The share of mild droughts in all periods of time is higher (Table 11). The significant change in this case is the low coefficient of variability, which varied from a minimum of $8.1 \%$ at a 12 -month scale to a maximum of $9.8 \%$ on a 24 -month scale. The share of drought is very high in the 6 -month time scale. On the other hand, the investigation of the drought persistence of Rasht station according to the SPI calculated at different time intervals 
shows that the incidence of drought is greater in the 3 and 6 months intervals, but in the 24-month intervals The lowest frequency is observed, while the duration of the drought is greater in the 12 and 24-month periods. The most severe drought occurred during the period (1956-2005) in the 12 months and 1965 at Rasht station (3.39). The longest drought period was from 1996 to 2000 . Which was the most severe drought in those years. The highest drought in the 1996 statistical period was four years, which began in 1996 and lasted for 2,000 years. Ishta (Figures 3 to 6 ).

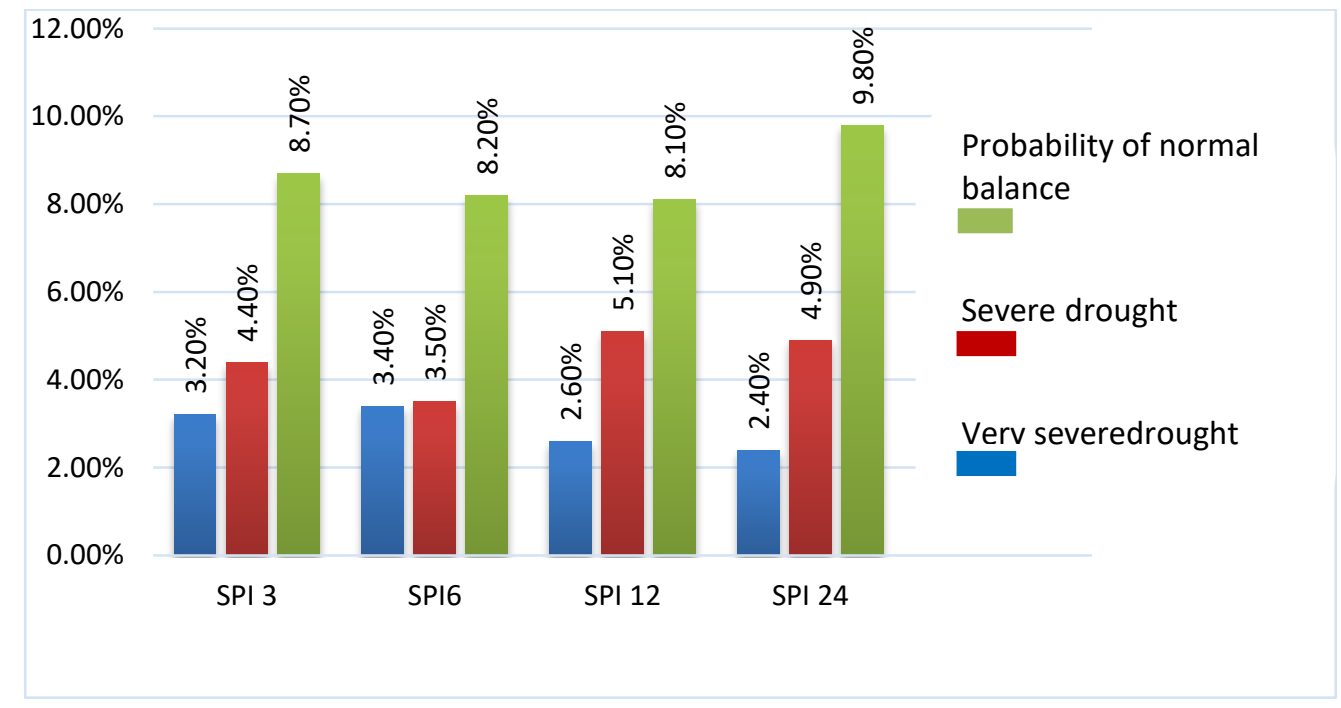

Figure 2: Percentage of different types of droughts in different time periods.

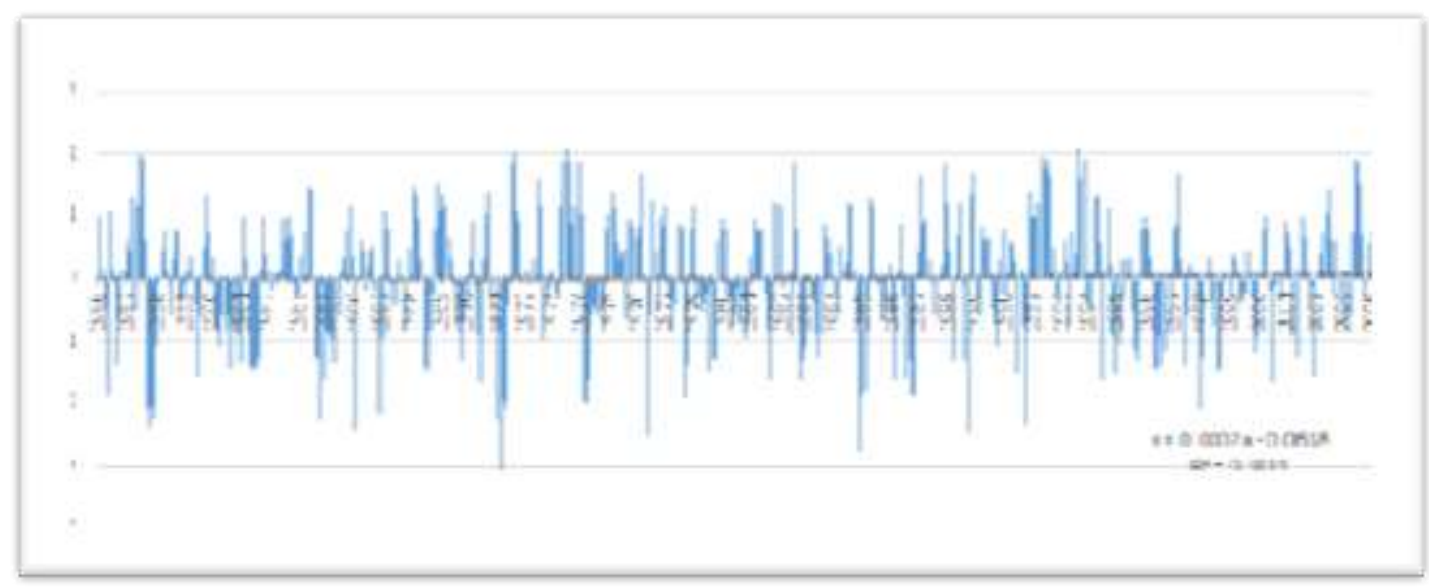

Figure 3: Frequency of drought incidence and duration and their period of continuation in the 3 month period. 


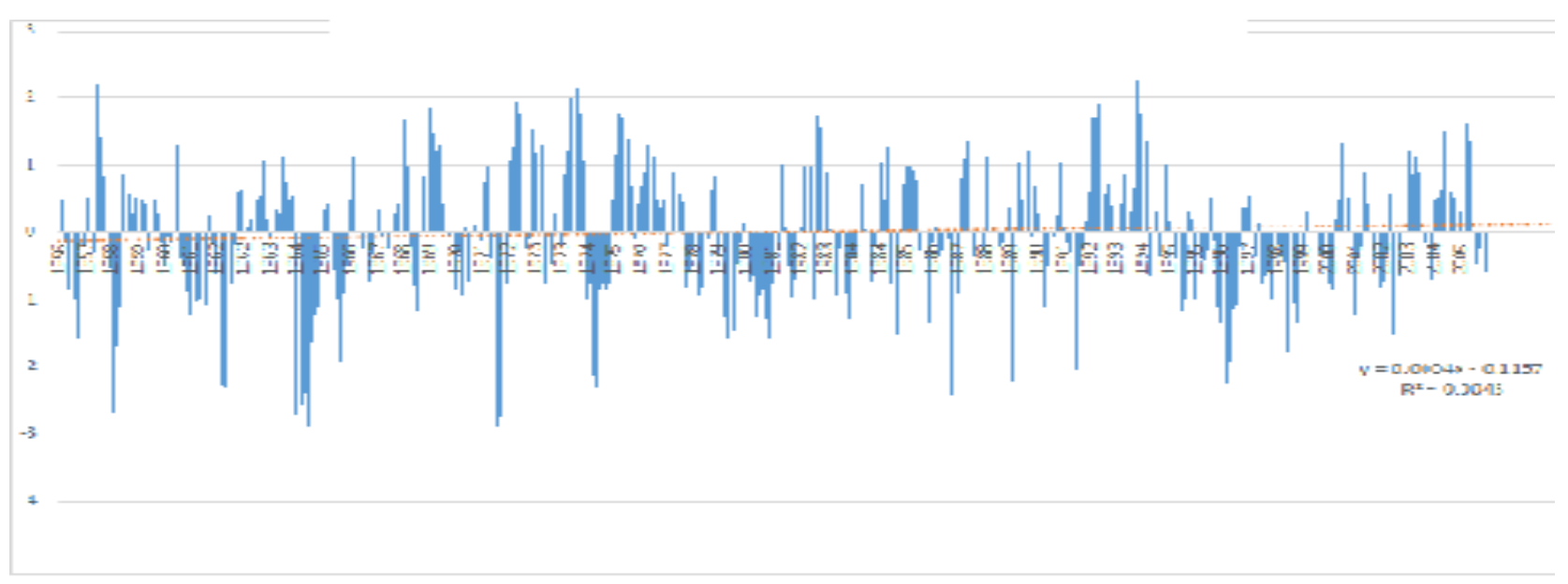

Figure 4: Drought and drought occurrence and their period of persistence in the 6-month period.

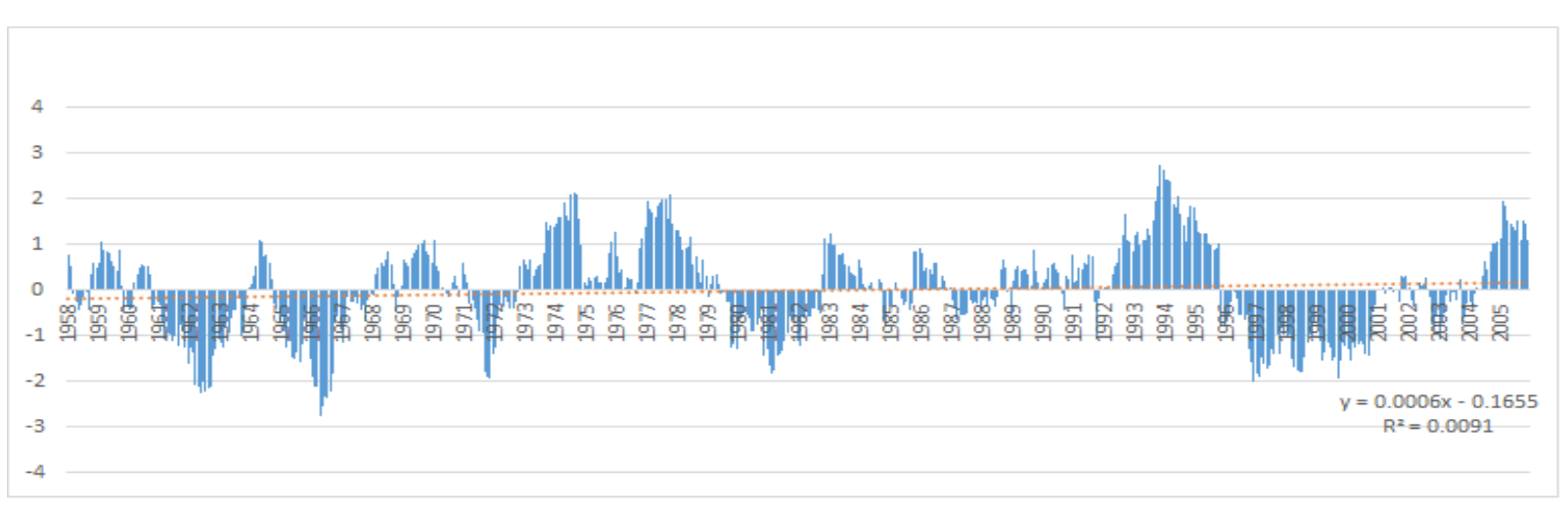

Figure 5: Prevalence of drought and traumatic occurrences and their continuity period in the 12-month period. 


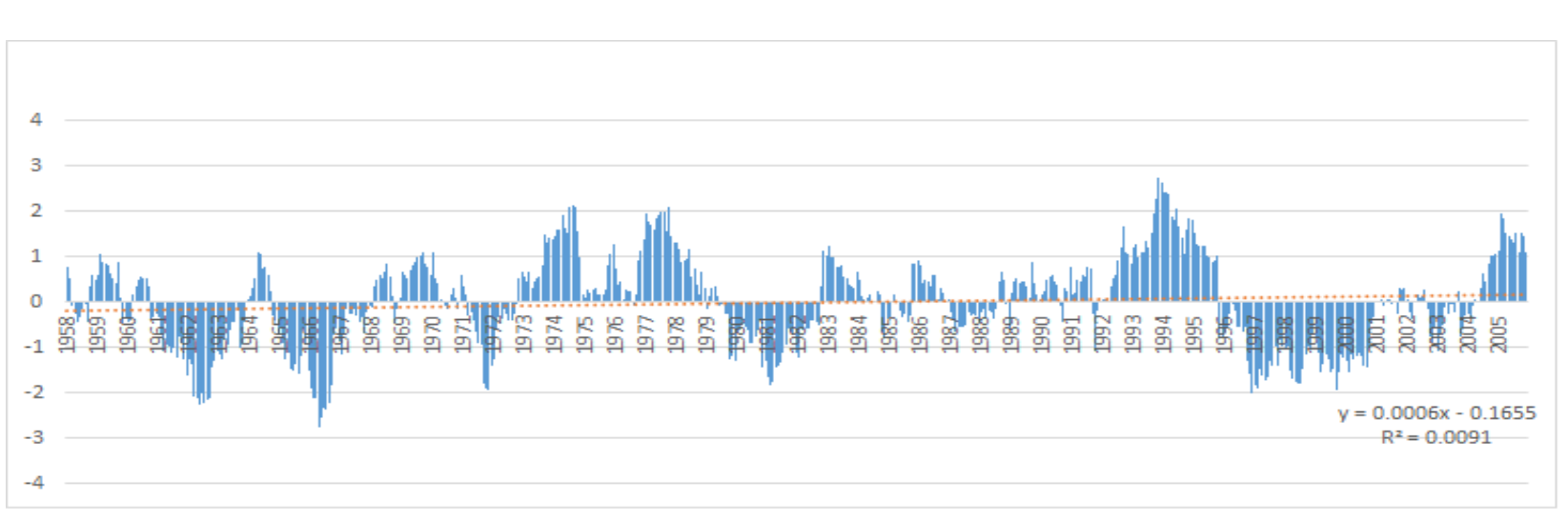

Figure 6: Prevalence of drought and traumatic occurrence and their period of continuity in the 24-month period.

With regard to the three general conditions considered, namely drought, maturation and normal period calculated in the form of $z$ or spi score (Table 4), it can be seen that the climatic conditions in Rasht are such that, apart from the 12-month period in other cases The probability of occurrence is higher than the probability of occurrence of drought. The probability distribution matrix of conditional transfer modes in time intervals (Table 5) indicates that the probability of transfer from one of the states.

Drought, fatigue, and normal are the same in the next step, while the likelihood of a transition from drought to mild and vice versa is very low, so that it is close to the maximum in the period of 3 and 6 months $(0.005$ and 0.002$)$ It is zero in the 12 and 24 -month period. The probability of transition from normal to drought is more than the probability of a transition from this state to life.

The probability of transition from one mode to another is longer in the series of longer periods. The probability of the transfer of nine in Table 5 shows that the probability of being in the city of Rasht is more than the other two conditions. It is also possible to shift from wet to wet periods at 3, 6 and 12 months, more than the probability of passing from the dry period to another similar period $(8.37 \%$ versus $8.21 \%$ over the three months and $9.76 \%$ in Against $9.26 \%$ over the six-month period and $14.4 \%$ against $13.89 \%$ over the 24 month period), while the probability of transition from dry state to the 12 -month period is similar (11.42\% versus $11.22 \%$ ). Considering the estimated values of the probability of equilibrium of dry, wet and normal periods (Table 7), it is shown that in all periods of time, the probability of normal state equilibrium is greater in Rasht city, but in longer intervals its amount is reduced to Which dropped from $0.57 \%$ over the period of 3 months to $0.41 \%$ over the 24 -month period, which is consistent with the cases experienced in each of the series. The probability of equilibrium between drought and drought periods increases from a period of 3 months to a 24-month interval. (Figures 3 to 6). In all periods of time, the probability of a longer-term equilibrium is greater than the probability of drought equilibrium (Fig. 7); meaning that in all-time series, the percentage of time that Rasht station stays in wet conditions is more than that when it is in dry condition. However, with the exception of the 6-month period, there is little to no time in the lasting period of persistence of drought. On the other hand, in the period of 24 months, the increase in the drought tragedy in Rasht has increased It adapts to the climate conditions of the region. According to Table 9, it can be concluded that the average number of predicted normal periods ranges from a short period to a longer period of time (from 118 in the 3 month period to 53 in the 24-month period). It is also possible to see a decrease in the number of estimated wet periods. From (42.4) the item is foreseen over the period of 24 months in the quarterly period to (8.4) cases. The probability of occurrence of normal periods of $P(n)$ calculated through the Markov chain model is 3 months (0.19) and 24 months (0.09), which is consistent with the climatic conditions. 


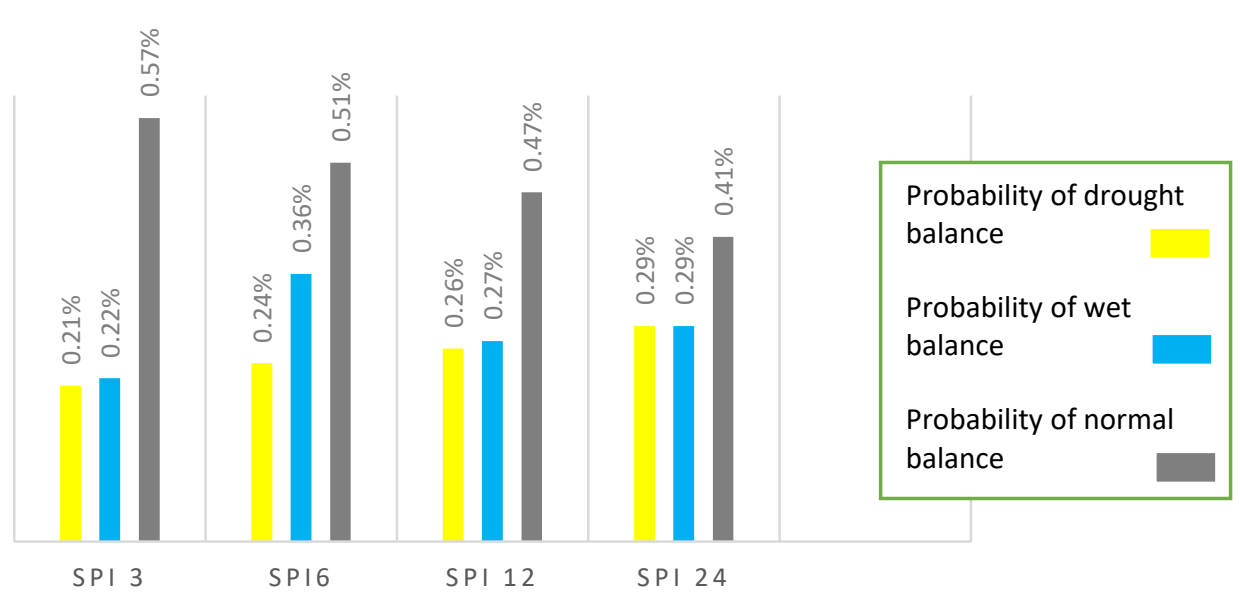

Figure 7: Frequency of Drought, Thoracic and Normal Equilibrium in Different Time Spaces Rasht station.

Figure 8 shows that, as in normal conditions, the average number of dry periods in long time series is higher than estimated over a short period of time. This trend is also a type of climatic time series trend that shows the average number of expected natural cycles. And they have declined from the short to the long term (118.8 vs. 53), although they show a stronger uptrend than the 12-month period.

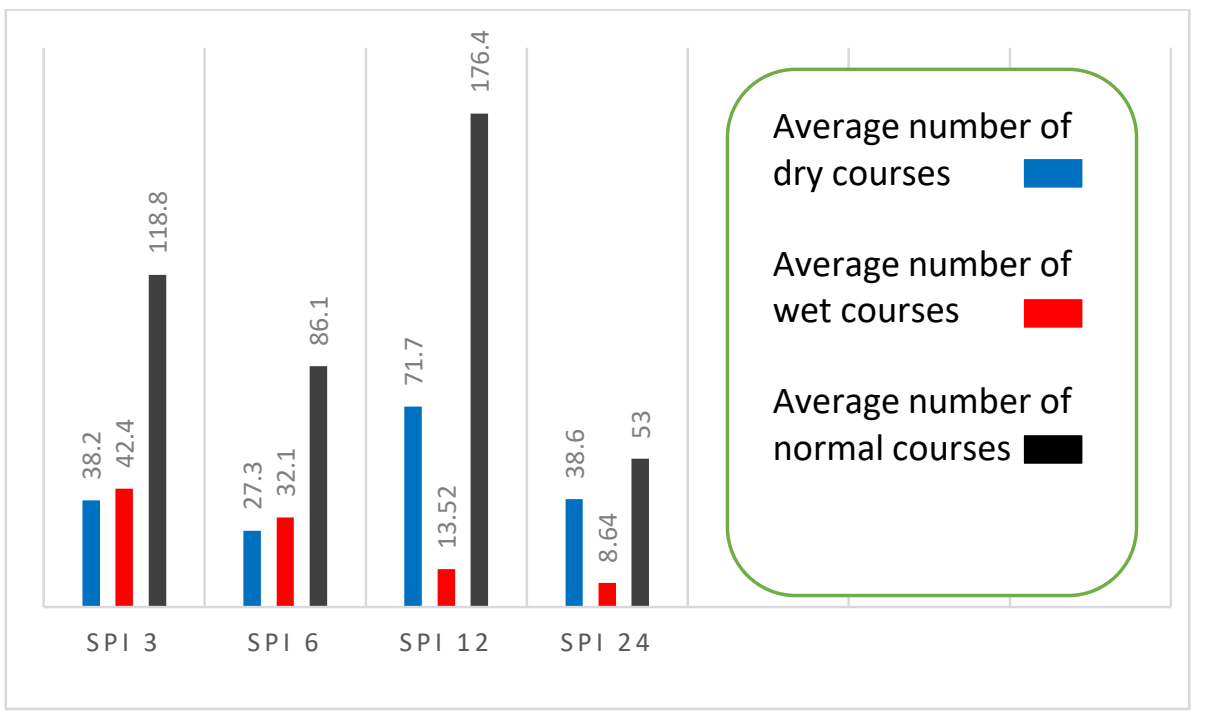

Figure 8. Average number of dry, wet and normal periods at different time intervals Rasht station.

Fig. 9 and Table 10 show that the average sustained duration and estimated drought from an interval of 3 months to a 24-month period is an incremental trend, compared with forms 3 to 6 , indicating the matching of estimated Markov count with the natural conditions of the area. 


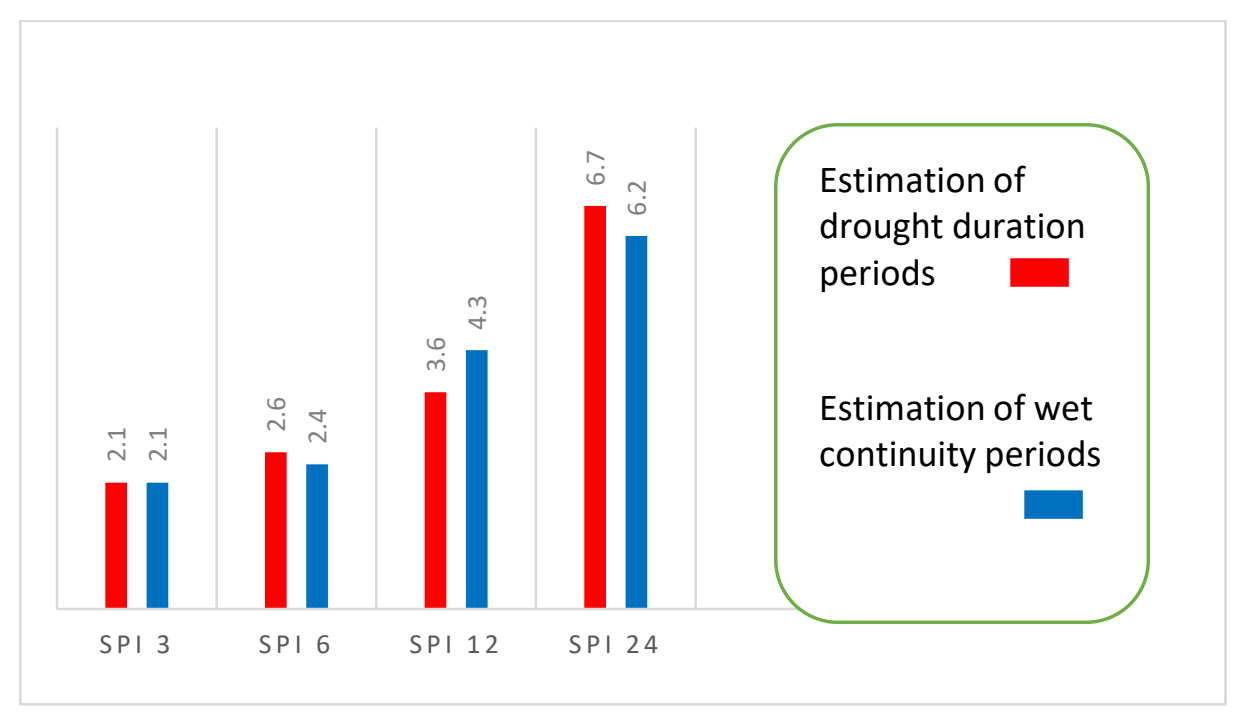

Figure 9: Average period of drought and wet persistence in various time intervals-Rasht station.

\section{Discussion and conclusion}

To study drought and estimate the probability of its occurrence in Rasht, which is located in the rainiest rainfall area of Iran, SPI time series were used in combination with Markov chain and the duration, intensity and frequency of drought and wet season for the period. 12, 6, 3 and 24 months were studied. The equilibrium probability in each of the drought, wet and normal conditions was calculated and the average expected drought and wet season, along with its average duration for different periods was predicted. The results showed that the contribution of mild drought in all periods and drought was very high. Drought has the highest frequency in the period of 3 and 6 months and the lowest in the period of 24 months. Wet equilibrium is more likely than drought equilibrium. The results of the SPI index are consistent with the results of the Markov chain, so the combination of the two, while enhancing our ability to assess and monitor drought, increases the efficiency of the resource management and planning system.

The survey shows that the probability of drought equilibrium in short and long term periods of 3 and 6 months is less than that of 12 and 24 months, and is strongly influenced by daily rainfall. The other results of this research are that the occurrence of drought with different persistence and magnitude at Rasht station is a common phenomenon and contrary to the general impression of the extreme conditions of drought has repeatedly been experienced. The final conclusion is that although the drought in Rasht compared with many other regions of Iran are not heavily affected, but it should be noted that it is important for two reasons why drought monitoring and its management in this city are important. First, the severity of the effects of drought, especially in longer periods of time in this area, causes the fragility of the environment to be more intense because many of the organisms in the area are not able to adapt to the changes and are eliminated to a large extent in the region. Secondly, rice as a major product of this region is very sensitive to water scarcity And the beginning of the cultivation operation, as well as the most sensitive period of its growth, namely flowering and sap, coincides with the least rainy days of the year of Gilan, spring and July, which is often faced with drought. Therefore, risk management requires careful examination of this situation so that we can rely on our knowledge of preparedness to better deal with and manage the risk conditions and minimize the consequences.

\section{References}

Fattahi, I., and Honesty, A. (2007). Analysis of curves of intensity, duration and frequency of fragmentation". Case study of selected stations in southwest of Iran. Geography and development magazine. Spring and summer.

Folger, P. (2013). Drought in the United States: causes and issues for congress" .1-37 PP.

Heidari and Yazdani (2001). Application of the Markov Chain in the Study of Drought and Susceptibility of Sistan Oblast in relation to the Hearmand River Flood. Conference on Exploring Water Conflict Resolution, Zabol University, 173-177.

Hejazizadeh, Z. and Joyazade S. (2010). Introduction to Drought and its Indicators. Tehran,side. 
Hong, W and Hayes, J. (2001). An Evaluation of the Standardized Odds Index. The China-Z Index and the statistical Z-Score Int. J. Climatol, 745-758 PP.

Mckee, B. T., Nplan, J., Doesken and Kleist, J. (1993). The relationship between drought frequency and duration to time. 8th, Conference on Applied Climatology, 17(22): 179-184.

Monacelli, G. (2012). Drought evaluation and forcasting" .4 to 7 May.1-137.PP.

Nielsen, W. (2007). Drought monitoring index for Texas". 1-53 pp.

Paulo, A. Coelho, C. and Pereira. L.S. (2003). Drought class transition analysis through the Markov and log linear model. Proceeding of the 6th Inter-Regional Conference on Environment-Water, Land and Water Use Planning and Management, Albacete, Spain.

Rezaei, T., Nasrin, P., Aristaneh, P., Aktari, R. and Saghafian, B (2007). The study of meteorological drought (climate) in Sistan

Baloochestan province using SPI index and Markov chain model. Journal of Water Resources Research, Vol. 36, No. 3, Autumn 92.

Sadeghi Nia, A., Hejazi Zadeh, Z., Hamidianpour, M. and Porsarband, N (2011). Estimation of Drought and Drought Probabilities Using SPI Index and Markov Chain Model, Tehran Case Study.

Svoboda ,M. (2009), Applying the standardized precipitation in the index as a drought indicator. September 14, 2009.

Thompson, S.A. (1990). A Markov and runs the analysis of drought in the central United States ", Physical Geography, 11 (3), $191-205$ $\mathrm{pp}$.

Tsakiris, G., Lucas, A. A., Pangalou, D., Prisoner, H. H. and Tigka D. D. (els). Drought characterization, 2012.PP.

Yousefi, N. A. and Irannejad, P. (2007). Estimation of Drought and Sustainable Extreme Using the Markov Model and Normal Distribution (Case Study of Qazvin). Geographical Research, No. 60, 121-128. 